\title{
Analysis on The Internationalization Risk of Chinese Household Appliances Enterprises and It's Valuation
}

\author{
CHEN Jing ${ }^{a}$, LIU Hong-liang ${ }^{b}$ \\ School of Economy and Management of Shenyang Aerospace University, Shenyang 110136, China \\ a08176@sina.com, ${ }^{\mathrm{b}} 342071425 @ q q . c o m$
}

Key words: household electric enterprise; internationalization; risk; valuation

\begin{abstract}
Based on the internationalization background of Chinese household appliances enterprises, all kinds of risk factors were analyzed, and the risk evaluation index system were set up through 20 observation indexes of four type risks. Then the analytic hierarchy process was introduced to evaluate the internationalization risk of Chinese household appliances enterprises quantificationally, which is a simple and practical measure for risk Valuation and risk management decision.
\end{abstract}

\section{Introduction}

As early as the mid - 90 - s of the last century, thinking about the enterprise's international operation had been begun when some domestic enterprises began to develop international operation. Such as Zhu Guanxin and Ma Chunguang (1994) ${ }^{[1], 2]}$, Zhao Shuming (1994) ${ }^{[3]}$ and so on, had put forward some proposal about internationalization for enterprise based on the enterprises internationalization in foreign countries.

Also Zhao $\mathrm{Yu}^{[4]}$ had put forward the "Power-Game" theory of internationalization, and tried to build a kind of practical theory which could guide the enterprises to internationalize in his new book: Internationalization Strategy-Theory, Model and China's Choice, in which three internationalization models of type $\mathrm{F}$, type $\mathrm{P}$ and type $\mathrm{C}$ had been put forward. It is an earlier book about enterprise internationalization.

Tang $\mathrm{Aili}^{[5]}$ and $\mathrm{Xu} \mathrm{Ming}^{[6]}$ analyzed the risks of enterprise internationalization in detail and put forward some management measures.

TO the internationalization of household appliances enterprises, the cause and mode selection and growth path have been analyzed in the most existing literatures, there was no one to research the internationalization risk of them. So in this paper, we will analyze on this and establish evaluation model.

\section{The Background of Chinese Household Appliances Enterprises’ Internationalization}

The background of household appliances enterprises' internationalization is as the following:

China has been the household appliances manufacturing center of the world. At present there are more than 1 thousand of household appliances enterprises, more than 120 kinds of household appliances can be produced and most of them have been sold in most countries and regions in the world. The production efficiency and cost of Chinese household appliances industry has reached advanced level in the world. Almost all the transnational household appliances enterprises have moved their manufacture base to China. China has been the main household appliances manufacture base.

Chinese household appliances industry has been in mature period. The profit of Chinese household appliances industry was as high as 20\% 30\% during its high speed development period since the $80 \mathrm{~s}$ to the mid - $90-\mathrm{s}$, but the profit of the whole household appliances industry has descended to $2 \% \sim 5 \%$ after the mid - $90-\mathrm{s}$, even some products to 0 , which shown that Chinese household appliances industry has been in mature period. Under this condition and the background of China has been the household appliances manufacturing center of the world, Chinese household appliances enterprises had to explore the international market to find new development space only. 
The capacity of Chinese household appliances industry is surplus seriously. The output of main household appliances in China has been the most in the world end to 2006. While the main household appliances enterprises have begun a new round expansion plan since 2011. So the international market is the sole choice to digest the surplus capacity of Chinese household appliances industry.

The global financial crisis and European Debt Crisis provided favorable chance for internationalization of Chinese household appliances enterprises. The global financial crisis does not end at present while the European Debt Crisis has become even more violent, which provided favorable chance for internationalization of Chinese household appliances enterprises.

\section{Analysis on the Risk of Chinese Household Appliances Enterprises' Internationalization}

analysis on the risk of Chinese Household Appliances Enterprises' Internationalization. Some detainment and confiscation events of Chinese enterprises' products have often been reported in media with more and more Enterprises gone abroad, which showed Chinese enterprises faced kinds of risks in the process of internationalization. How to evaluate, avoid and control the risks is an unavoidable issue in the process of internationalization.

Trough analyzing some risk events of Chinese enterprises' internationalization, we can see that the risk type is closely related with the internationalization way that the enterprises chosen except for the universal risks, even the emphasis of the universal risks are different because of the different internationalization way. To Chinese household appliances enterprises, the main internationalization risks are as the following combining with all kinds of risk events and the analysis in existing literature:

The first is environment risk. That is the uncertainty of business environment in host country brings about risks to enterprises, include political risks, law risks, consumption level and structure risks, economy structure risks and safety risks.

The second is cultural risk. The enterprises will enter into different culture environment inevitably when they internationalize. So the difference of different culture may lead to culture misunderstand, culture conflict or cognition and so on, which bring about risks to enterprises, include ideology risks, thinking model risks, behavioral pattern risks and religious belief risks.

The third is market risk. That is the uncertainty of the market in host countries brings about risks to enterprises, include client self-identity risks, service risks, market capability risks, personalized demand risks, market competitiveness risks and distribution channel risks.

The fourth is finance risk. That is the uncertainty of finance brings about risks to enterprises, include cash flow risks, profit level risks, exchange risks, credit risks and credit aid risks.

Based on the analysis on above, the evaluation indexes of the household appliances enterprises' internationalization risk are set up shown as Table 1.

\section{Evaluation the Risk of Chinese Household Appliances Enterprises’ Internationalization}

Table 1. the evaluation indexes of household appliances enterprises' internationalization risk

\begin{tabular}{|c|c|c|c|c|}
\hline \multicolumn{5}{|c|}{ Internationalization Risk of Household Appliances Enterprise (A) } \\
\hline $\begin{array}{c}\text { Risk } \\
\text { Factors }\end{array}$ & $\begin{array}{c}\text { Environment Risks } \\
\text { (B1) }\end{array}$ & $\begin{array}{c}\text { Cultural Risk } \\
\text { (B2) }\end{array}$ & Market Risk (B3) & Finance Risk (B4) \\
\hline
\end{tabular}




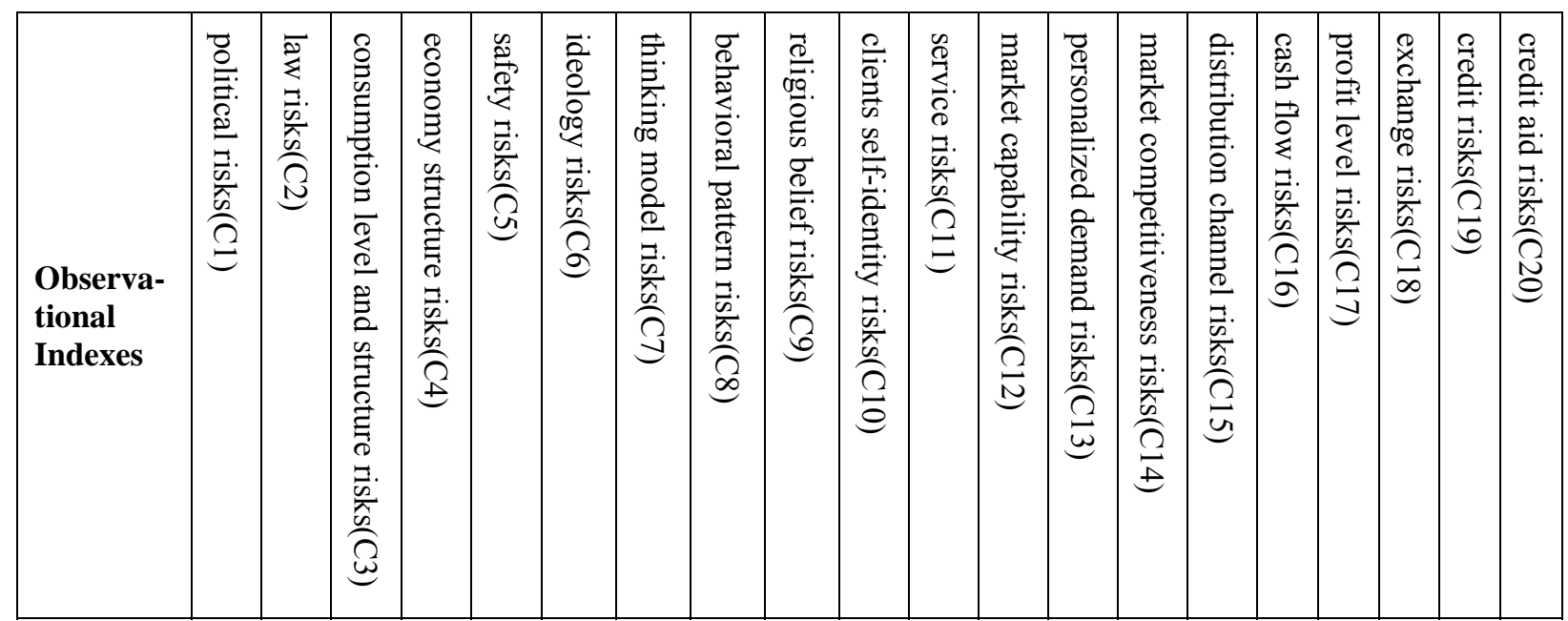

Based on the method of multi-objective decision, we use the analytic hierarchy process put forward to evaluate the risk of Chinese household appliances enterprises' internationalization by Pro. T.L.Saaty. The assessment process is as the following:

To found the evaluation index system. The risk of Chinese household appliances enterprises' internationalization is as a system based on the theory of the analytic hierarchy process. We can found the evaluation index system include 4 hierarchies and 20 observational indexes shown as table 1 .

To found the judgment matrix A. The judgment matrix A can be founded through numbers which signify the relative importance between the lower hierarchy factor and the upper hierarchy factor. T.L.Saaty had put forward a method of 1-9 ranks shown as table 2.

Table 2. the judgment matrix and its implication

\begin{tabular}{c|l}
\multicolumn{1}{c|}{ scales } & \multicolumn{1}{c}{ implication } \\
\hline 1 & Means the two factors have same importance \\
\hline 3 & Means one factor is a little more important than the other \\
\hline 5 & Means one factor is more important than the other \\
\hline 7 & Means one factor is strongly more important than the other \\
\hline 9 & Means one factor is extremely more important than the other \\
\hline $4 、 6 、 8$ & Means the importance compared with the two factors is in the middle of the scales on above \\
\hline reciprocal & Means if the ratio of factor $\mathrm{i}$ with factor $\mathrm{j}$ is $\mathrm{a}_{\mathrm{ij}}$, then the ratio of factor $\mathrm{j}$ with factor $\mathrm{i}$ is $1 / \mathrm{a}_{\mathrm{ij}}$ \\
\hline
\end{tabular}

When there are multi-factors, the indexes corresponding to each risk factor should found judgment matrix in order to calculate the ultimate weight of each risk factor.

To order the hierarchy list. We can work out the eigenvalue of maximum $\lambda_{\max }$ of judgment matrix A, then use the formula: A $\bullet \omega=\lambda_{\max } \cdot \omega$ to work out the eigenvector $\omega$ corresponding to the $\lambda_{\text {max }}$. That is the weight order of the relative importance of the element in this hierarchy to the upper hierarchy after standardized.

To check consistency. We can't require all judgment matrixes are consistent, but most of them should be primarily consistent. So we need to check the consistency of judgment matrix A. The process is as the following:

The first is to work out the consistency index CI of judgment matrix A: 


$$
\mathrm{CI}=\left(\lambda_{\max }-\mathrm{n}\right) /(\mathrm{n}-1)
$$

The letter $\mathrm{n}$ in the formula is the rank of judgment matrix $\mathrm{A}$. When $\mathrm{A}$ is completely consistent, $\mathrm{CI}=0$. The result of $\lambda_{\max }-\mathrm{n}$ is greater the consistency of judgment matrix is worse. We need to compare CI with average random consistency index RI, when we judge if the judgment matrix has satisfying consistent. That is to work out CR:

$$
\mathrm{CR}=\mathrm{CI} / \mathrm{RI}
$$

To the judgment matrix of 1-9 ranks, T.L.Saaty had worked out the number of RI, shown as table 3 .

Table 3. the RI number of random consistency index

\begin{tabular}{|c|c|c|c|c|c|c|c|c|c|}
\hline ranks & 1 & 2 & 3 & 4 & 5 & 6 & 7 & 8 & 9 \\
\hline RI & 0.00 & 0.00 & 0.58 & 0.9 & 1.12 & 1.24 & 1.32 & 1.41 & 1.45 \\
\hline
\end{tabular}

When $\mathrm{CR}=\mathrm{CI} / \mathrm{RI}<0.1$, we can judge that the judgment matrix has satisfying consistent, if not we should adjust $\mathrm{A}$, until reaches satisfying consistency.

To work out the weight system of every risk factor. If the judgment matrixes of the risks on above have passed the consistency check, we can get the weight system of risk factors through transforming the result of eigenvector $\omega$ corresponding to the $\lambda_{\max }$ in the hierarchy list.

\section{Peroration}

The method of analytic hierarchy process has been used to divide the complex risks of household appliances enterprises' internationalization into correlative and orderly hierarchies. And a simple and practical method of risk evaluation and making management decision was provided, which is more scientific and reasonable than personal experience.

\section{References}

[1] Ma Chun-guang. Comparation of Business Internationalization Models and Recommendation to Chinese Enterprises' Internationalization [J]. World Economy.1994（6): 59-64.

[2] Zhu Guan-xin. Some Problems of Chinese Enterprises' Internationalization [J]. Chinese Industrial Economy Research.1994 (3): 71-72.

[3]. Zhao Shu-ming. The Strategic Thinking on Chinese Enterprises' Internationalization [J]. Jiangsu Social Sciences.1994 (5): 3-8.

[4] Zhao Yu. Internationalization Strategy-Theory, Model and China's Choise [M].Press of Nankai University.1996.

[5] Tang Ai-li. Analysis on the Risk of Chinese Enterprises' Internationalization and the Strategy of Risk Management[J]. China Market.2007 (26): 30-31.

[6] Xu Ming. Risk Management of Enterprises' Internationalization [J]. China National Conditions and Strength.2009 (12): 49-52. 